\title{
IMÁGENES POÉTICAS EN TEXTOS DE VIAJES ROMÁNTICOS AL SUR DE ESPAÑA
}

\author{
LEONARDO ROMERO TOBAR \\ Universidad de Zaragoza
}

\begin{abstract}
RESUMEN
Una marca artística que otorga a los relatos de viajes la condición de «género literario» es el empleo de imágenes poéticas que el viajero asocia con aspectos de los lugares visitados. Estas páginas dan una selección de imágenes empleadas por viajeros a Andalucía durante el siglo XIX. La imagen más frecuente es la que remite al tópico cultural troquelado sobre la bipolaridad Norte/Sur; también se recuerdan otras metáforas con las que fue descrito Cádiz en sus connotaciones de paisaje rodeado de mar y belleza luminosa que fue trasladada a la belleza de sus mujeres.
\end{abstract}

Palabras clave: Imágenes poéticas, relatos de viajes, bipolaridad Norte/Sur, visión metafórica de Cádiz.

\section{POETIC IMAGES IN WRITINGS OF ROMANTIC TRAVELS TO SOUTHERN SPAIN}

\begin{abstract}
The poetical image reported to the visited places is an artistic device that makes travel books a «literary piece of work». In this article I offer an anthology of the images about Andalucía given by their visitors in the XIXth Century. The most common image is about the bipolarity North/ South, but there are and we can read many other images: the brilliant metaphors used to described Cádiz as a «sea-shell» or a «ship» and specially for describing the charm of women there.
\end{abstract}

Key Words: Poetic images, voyage report, bipolarity North/ South, metaphors for Cadiz.

Desde el punto de vista de la creación literaria, un aspecto singularmente expresivo de los modernos libros de viajes reside en las imágenes poéticas con las que sus autores trasladan su visión personal de los lugares que han visitado y de los que escriben. Procedimientos como la reescritura de otros textos, la utilización de un léxico especializado en su semántica de base estética, la fórmula de enunciación empleada — relato en tercera persona, diario, cartas, notas sueltas...- o el subrayado estilístico de la percepción 
subjetiva han sido ampliamente atendidos en la bibliografía crítica dedicada al género literario que me ocupa, bien en su dimensión general, bien en el análisis aplicado a textos particulares ${ }^{1}$. Ahora bien, el empleo de metáforas encaminadas a sugerir las asociaciones de diverso tipo que alguna realidad observada en el curso viaje suscita en el viajero es otro recurso, de eminente naturaleza poética, que merece la pena ser tenida en cuenta en la lectura de esta clase de textos, ya que se trata de un procedimiento que distancia el relato de viaje de su dimensión informativa y documental para proyectarlo sobre el fondo inextinguible de la escritura artística intensificando su valor como texto literario.

En las páginas que siguen presento un breve compendio de imágenes poéticas presentes en libros de viajes realizados al Sur de la península Ibérica y en las que, además de la original iluminación que aportan al referente concreto, establecen matices significativos que apuntan a concepciones culturales de más ancho alcance.

\section{EL SUR COMO IMAGEN POÉTICA Y CULTURAL}

Tanto los puntos cardinales como la rosa de los vientos, más allá de su valor como términos técnicos que denominan la organización y la dinámica del espacio geográfico ${ }^{2}$, han servido también para construir modelos metafóricos con los que se ha explicado la organización de la realidad. Sólo el título de algunas obras literarias sirve la prueba de lo dicho: el poemario West-östlicher Diwan de Goethe, la pieza teatral South Pacific de Rodgers y Hammerstein, el relato épico de John Steinbeck East of Eden o la reciente novela de Adelaida García Morales El Sur. Y en ese inextinguible territorio que interrelaciona puntos cardinales y escritura literaria voy a detenerme en una imagen recurrente que articula la visión de dos mundos opuestos por el vértice, la imagen que contrapone Norte y Sur para generar una polaridad extrema entre dos modelos de cultura en las que resultan determinantes las impresiones sensoriales que evocan ambos nombres. Lo troqueló poéticamente Goethe en estos versos:

${ }^{1}$ Un modelo sobre textos de viaje estudiados desde una perspectiva analítica de las palabras-clave del léxico estético empleadas por los viajeros puede verse en el libro de Esther Ortas Viajeros ante el paisaje aragonés (1759-1850). Zaragoza: Institución Fernando el Católico, 1999, que en su origen fue un trabajo de investigación que yo había encauzado y dirigido en la Universidad zaragozana.

${ }^{2}$ Las transferencias entre el signo cardinal y el nombre de un viento constituyen también testimonios muy elocuentes de la virtualidad significativa que poseen ambos campos léxicos; por ejemplo, para la analfabeta Fortunata, el inolvidable personaje galdosiano, informa el narrador de la novela que «no sabía lo que es el Norte y el Sur. Esto le sonaba a cosa de viento, pero nada más» (Fortunata y Jacinta, parte Segunda, cap. II «Afanes y contratiempos de un redentor»). 
Kennst du das Land wo die Zitronem blühn, Im dunkelin Laub die Gold-Orangen glühn, Ein sanfter Wind vom blauen Mimmel weht, Kennst du es wohl?

Dahin! Dahin!

Möcht'ich mit dir, o mein Beliebter, ziehn³ .

Los anteriores versos que inician la canción de Mignon en la novela Whilhelm Meister Lehrjahre (1796, libro III, cap. I) fueron un excitante estímulo poético para la invitación al viaje a Italia, el privilegiado enclave del Sur europeo que había atraído a tantos viajeros antes de esta obra y después de su publicación. La canción de Mignon vuelve a sonar en textos teatrales o narrativos como en la ópera de Ambroise Thomas Mignon ${ }^{4}$ (estrenada en 1866) o en la novela barojiana El mundo es ansí ${ }^{5}$ (1912). Una imagen que una viajera alemana - la esposa de Guillermo von Humboldt, Carolina - asociaría directamente con las tierras meridionales de España cuando escribe a su amiga Lotte Schiller: «Cuando vi los primeros naranjos cerca de Córdoba, comencé a cantar Kennst du das Land...» ${ }^{6}$. Italia, España, el sur de Francia, Grecia, la península balcánica son denominaciones topográficas que remiten al profundo Sur, el arquetipo cultural que se había ido construyendo en el curso del XVIII sobre la bipolaridad Norte/Sur.

El color y el perfume de los cítricos evocados en el poema de Goethe se entrelaza con la grata sensación del aire y con los efectos de luz y sombras que se desplazan entre el follaje del arbolado que enmarca la escena entrevista. Las estimulantes sensaciones no podían producirse en otros paisajes como los del Norte brumoso, donde los frutos aludidos resultaban un producto desconocido, casi un exotismo propio del Oriente, otro punto cardinal con el que se relacionaba inevitablemente al atractivo Sur.

${ }^{3}$ « ¿Conoces el país donde florece el limonero,/ brilla en el oscuro follaje la naranja de oro,/ una sueva brisa sopla azul del cielo,/ está el mirto callado y el laurel crecido/ Lo conoces bien?/ ¡Allí! ¡Allí!,/ ¡oh, querido mío! quiero marchar contigo».

4 «Connais tu le pays où fleurit l'oranger?/ Les pays des fruits d'or et des roses merveilles,/ où la brise est plus douce et l'oiseau plus léger,/ où dans toute saison butinent les abeilles,/ où rayonne et sourit, comme un bienfait de Dieu,/ un éternel printemps sous un ciel toujours bleu!/ Hélas! Que ne puis-je te suivre/ vers ce rivage hereux d'où le sort m'exila/ C'est là! C'est là que je voudrais vivre,/ aimer, aimer et mourir/ C'est là que je voudrais vivre, c'est là,/ oui, c'est là».

${ }^{5}$ La situación narrativa corresponde al momento en el que la protagonista Sacha Savarof visita el taller del encuadernador y padre del que será su primer esposo, Ernesto Klein: «Por la ventana de la guillotina entraba un rayo de sol, y en la calle una mendiga tocaba en un organillo de mano aquella melodía de Mignon de Thomas, Connais-tu le pays où fleurit l'oranger, y Sacha creía encontrase en un mundo de sueño, en el taller de algún viejo artífice de la Edad Media» (Primera parte, cap. IX, «Esa luz en el horizonte de la juventud»).

${ }^{6}$ Dato exhumado por FARINELLI. (Guillaume de Humboldt et l'Espagne. Avec une esquisse sur Goethe et l'Espagne. Torino: Boca, 1924, p. 141) que añade otras asociaciones del Sur de España con una eterna primavera embalsamada del perfume de los naranjos, registradas por Jean Paul (en su Titan) o Clemens Brentano en carta a su hermana Bettina. 
Desde las consideraciones de Montesquieu acerca dela idea de «civilización» y a partir de los aportes factorialistas que fijaban en los diversos climas atmosféricos las raíces de las civilizaciones, Mme. de Staël organizó un esquema histórico-cultural en el que, sumando a la dicotomía Norte/ Sur la vieja oposición antiguos/modernos, avanzaba un modelo dinámico para interpretar a los distintos pueblos y sus literaturas en una perspectiva de comparación plurinacional. A partir del capítulo VIII de su difundido libro De la littérature considerée dans ses rapports avec les institutions sociales (1800) fue estableciendo las marcas que para ella distinguían a los pueblos del Norte de los del Sur para preferir a los primeros porque estaban más alejados del fanatismo y la superstición 7 .

La bipolaridad Norte/Sur tipificada por la señora de Coppet sería prolongada en obras posteriores en las que se enriquecen y matizan los planteamientos de la autora franco-suiza. Escritores vinculados a su círculo de influencia cultural — Simon de Sismondi en De la Littérature du midi de l'Europe (1813), Charles-Victor de Bonstetten en L'homme du Midi et l'homme du Nord (1824)_ y profesores especializados en la sistematización de la historia literaria —Bouterweck (1804), Abel-François Villemain (1830), Jean-Jacques Ampère (1830), Puibusque (1843) entre otros- prolongarían la construcción del estereotipo sobre los añadidos de los convencionales valores adjudicados a los sexos - Norte viril/ Sur femenino- y el subrayado de la influencia oriental e islámica en las tierras de la Europa meridional ${ }^{8}$.

Si a los componentes generales que servían para caracterizar a la Europa del Sur se sumaba, en el caso de la cultura hispana, la recuperación de Calderón como el poeta que mejor compendiaba la caballerosidad y el ímpetu católico — una dirección de la teoría romántica que habían consolidado los hermanos Schlegel en los primeros años del $\mathrm{XIX}^{9}$ - , el resultado era una visión del Sur español que fundía rasgos del paisaje natural e impresiones sensoriales, prejuicios ideológicos y arquetipos de representación cultural, por lo que la vigencia del topos Norte/ Sur aparece en textos de la más variada naturaleza ${ }^{10}$. Podemos leerlo en alusiones al teatro calderoniano, tal

${ }^{7}$ LEGUEN, B. «Madame de Staël en la encrucijada de las Literaturas del Norte y del Sur». AA.VV. Estudios de Literatura Comparada (....). En: Actas del XIII Simposio de la Sociedad Española de Literatura General y Comparada. León: Universidad, 2002, pp. 171-182.

${ }^{8}$ Cf. LEGUEN, B. Art. cit. en nota 7. Para la «orientalización» de las literaturas modernas de la cuenca mediterránea, César Domínguez «The South European Orient: A Comparative Reflection on Space in Literary History». Modern Language Quarterly, 2006, 67-4, pp. 419-449.

${ }^{9}$ ROMERO TOBAR, Leonardo. «Romanticismo e idea de España y la nación española». Madrid: Fundación Ortega y Gasset, 2011, en prensa.

${ }^{10}$ Mme. de Staël reitera el topos al describir el efecto que causaron las conferencias vienesas de 1808 en las que August Wilhelm Schlegel habló del teatro español: «Los oyentes quedaron conmovidos por el cuadro que presentó y la lengua alemana, empleaba por él 
como escribía Goethe ${ }^{11}$ en 1816 o, muy probablemente, Böhl de Faber en $1818^{12}$. Perseguir la carrera de esta fórmula produciría una extensa antología de textos que, para cerrar a principios del siglo $\mathrm{XX}$, cifro en la descripción azoriniana que, en 1905, recrea la intensa vida de las calles sevillanas en las que la luz, los cantos de los pájaros, las músicas de los organillos y los cadenciosos movimientos de los viandantes «nos hacen pasar agradablemente entre las cosas, lejos de las quimeras y los ensueños hórridos de los pueblos del Norte» ${ }^{13}$.

A todo lo dicho debe añadirse que los viajeros a la Península trasladaron el esquema Norte/Sur a su propio viaje puesto que el paso de Sierra Morena les hacía patente la visión de dos polos paisajísticos e, incluso, culturales de la Península: el del Norte, austero y horizontal, y el del Sur, luminoso, alegre y plagado de reminiscencias arábigas. Lo expresaba, por ejemplo, el norteamericano Henry W. Longfellow en el capítulo «España» de su libro Outre-mer en que describe su visita a la Península en 1827:

Mis recuerdos de España son de los más vivos y deliciosos. La índole del país y de sus habitantes, las borrascosas montañas y los libres espíritus del Norte, la pródiga y exuberancia y ufana voluptuosidad del Sur, la historia y las tradiciones del pasado, más semejantes a la fábula romancesca que a la austera crónica de los acontecimientos, un idioma suave y no obstante, majestuosos, que resuena como música marcial, y una literatura rica en los atrayentes géneros de

con elegancia, rodeaba de pensamientos profundos y de expresiones sensibles los resonantes nombres españoles, estos nombres que no pueden ser pronunciados sin que la imaginación crea estar viendo los naranjos de Granada y el palacio de los reyes moros» (trad. mía de De l'Alemagne. Paris: Hachette, 1959, III, pp. 339-340).

11 «Estas obras (de Calderón) nos trasladan a una tierra gloriosa bañada por el mar, abundante en frutos y flores y medida por claras constelaciones; y al mismo tiempo a la época cultural de una nación de la que apenas podemos formarnos una idea... Debo agregar una cosa más: que mi estancia poética en Oriente sólo hace que el excelente Calderón (que no puede negar su trasfondo árabe) sea aún más estimado, tal como uno redescubre felizmente y admira a los nobles progenitores en sus valiosos nietos» (en carta a su traductor Johann Diederich Gries de 29-V-1816; ed. en Goethes Briefe, Hamburg, Wegner, 1965, III, p. 355).

${ }^{12}$ De un artículo en alemán aparecido en la revista Isis en el que se informa acerca del viaje de los naturalistas Alton y Pander a Cádiz para estudiar la «sepia octopus» y sobre el interés de estos sabios en el teatro calderoniano: «Embebidos, empapados en el acatamiento que el discursivo y despreocupado Schlegel ha inspirado nuevamente a favor del primero de nuestros muchos y apreciables dramáticos, llegaron a España, ardiendo con más actividad el volcán del entusiasmo que sentían en sí y enardece a los mayores literatos del Norte. Pero ¡qué dolor!, lo hallaron apagado. En cuarenta y dos días que residieron en la capital de España y patria de su amado poeta, no tuvieron el gusto de que se representase ningún drama de Calderón» (trad. mía de PITOLLET, Camille. La querelle caldéronienne de JohanNikolas Böhl von Faber et José Joaquín de Mora. Reconstituée d'après les documents originaux. Paris: Alcan, 1909, pp. VIII-IX).

${ }^{13}$ AZORÍN. Los pueblos. La Andalucía trágica y otros artículos (1904-1905). Valverde, J. Ma (ed.). Madrid: Castalia, 1973, p. 242. 
la lírica y la novela; esas, pero no esas solamente, eran mis reminiscencias de España $^{14}$

Y otro norteamericano, el joven George Ticknor en 1818, al describir su llegada a La Carolina, fijaba los vivos contrastes que se dan entre los paisajes situados respectivamente al Norte y al Sur de Sierra Morena, asociando Italia con Andalucía en una vivencia reiterada del topos Norte/ Sur:

La colonia completa [La Carolina], extendiéndose desde el pie de Sierra Morena hasta cerca de Bailén, forma un contraste singular por su limpieza e industria con la escuálida pobreza propia de los pueblos de La Mancha y Castilla. Fue en este encantador lugar donde primero observé el cambio de clima esperable al pasar una cadena montañosa tan importante. La delicada suavidad del aire de la tarde, justo como la había sentido un año antes al descender los Alpes, la reaparición de los olivares que son tan raros y escasos en Castilla y las plantes de los aloes, que no había visto desde que dejé la costa de Cataluña, todo probaba que había llegado a lo que podría llamar con propiedad la Italia de España ${ }^{15}$.

Como es sabido, la ruta española habitual de los viajeros procedentes de Europa descendía desde Castilla a Andalucía para atravesar Sierra Morena; el camino inverso no era tan frecuente aunque en la novela fantástica de Ptocki Manuscrit trouvé à Saragosse (1794-1815) los alucinantes personajes que la recorren proceden de más allá del estrecho de Gibraltar. Con todo, la asociación del Sur con los paisajes sagrados de Palestina podemos encontrarla en la ruta hacia el Sur por la costa levantina, tal como la establece el danés Hans Christian Andersen $(1862)^{16}$, o también la hallamos en la fascinación por los naranjos que se expresa en un viajero del sur del Sur, el canario Alonso Nava y Grimón en su Diario de viaje a Andalucía (1808).

Quedaba, en fin, el acceso a la Península desde los puertos marítimos del Mediterráneo, ya fuera el enclave británico de Gibraltar, los puertos comerciales de Barcelona, Valencia o Alicante o el menos frecuentado y atractivo puerto de Málaga ${ }^{17}$. Los propósitos más específicos que movían a

${ }^{14}$ LONGFELLOW, Henry H. Outre-mer. A pilgrimage beyond the sea. Boston-New Yok, 1891, p. 139.

${ }^{15}$ Doy la traducción del Diary de Ticknor tal como la ha realizado Antonio Martín Ezpeleta en la edición completa del manuscrito original conservado en la biblioteca de la Universidad de Darmouth y que se publicará en la serie «Clío y Calíope» de las Prensas Universitarias de Zaragoza.

${ }^{16}$ «Durante la jornada de aquel día había rodado ante nuestros ojos un paraje extraordinario, una naturaleza evocadora de los relatos que solemos leer sobre Tierra Santa. Habíamos cruzado por asoladas estepas de piedra, apagado nuestra sed con el agua tibia de las cisternas; los rayos del sol abrasaban como en los valles de Palestina; en la atmósfera candente nos solazábamos a la sombra de las palmeras, como hiciera el rey David y como hicieran los apóstoles en sus largos recorridos (Viaje por España, trad. del danés de Marisa Rey. Madrid: Alianza, 2005, p. 82).

${ }^{17}$ KRAUEL, Blanca. Viajeros británicos en Málaga (1760-1855). Málaga: Diputación Provincial, 1988. 
muchos de estos viajeros hacían de su travesía un recorrido espacial limitado, tanto en el espacio como en las observaciones que registraban en su caminar. Algunos, como el norteamericano Washington Irving ${ }^{18}$, concentraron sus notas en los datos sobre las personas con las que mantuvieron comunicación personal, y otros viajeros, como el inglés Thomas Roscoe ${ }^{19}$, perfilan su pluma en los detalles de comportamientos pintorescos o en el contraste estético de las ciudades que visitaban.

Pero fuera cual fuese la vía de acceso al Sur peninsular, el estereotipo de la antítesis «Norte/Sur» nunca dejó de funcionar en un estereotipo en el que el Sur aparecía como la visión de un paraíso o un jardín maravilloso, marcado por la pobreza gozosa de sus genuinos tipos humanos - toreros, bailarinas, bandidos, gitanos, contrabandistas-y por las huellas aún visibles de la cultura oriental. La pintura de género ejecutada a lo largo del siglo XIX y que tan buenos compradores encontraba entre los visitantes extranjeros confirma esta construcción del paisaje andaluz, tal como la han sistematizado estudiosos de la ciencia geográfica ${ }^{20}$.

\section{OTRAS IMÁGENES}

Muchos enclaves andaluces, desde las ciudades más populosas hasta los lugares recónditos o los paisajes pintorescos de la geografía natural, suscitaron extensos comentarios y estimaciones de los viajeros. En el caso de las ciudades se observa una tendencia a contraponer unas con otras partiendo de sus edificios y colecciones de arte o del ambiente social —incluso de las tertulias de personajes ilustrados- que los viajeros pudieron frecuentar ${ }^{21}$. Estudiar en detalle estos aspectos debe ser objeto de una extensa monografía, para la que estas páginas son exclusivamente el punto de partida en una orientación lectora de los «libros de viajes» que debería focalizarse en el empleo de las imágenes de tonalidad poética presentes en las descripciones de los lugares visitados.

Ofrezco seguidamente una reducida selección de metáforas con las que algunos viajeros representaron a Cádiz, la ciudad de leyenda por su origen

${ }^{18}$ IRVING, Washington. Diary. Spain 1828-1829. New York: The Hispanic Society of America, 1928.

${ }^{19}$ ROSCOE, Thomas. The Tourist in Spain. Andalusia by... Illustrated from drawings by David Roberts. London: Robert Jennings and Co., 1836.

${ }^{20}$ LÓPEZ ONTÍVEROS, Antonio. «Del prerromanticismo al romanticismo: el paisaje de Andalucía en los viajeros de los siglos XVIII y XIX». En: AA.VV. Estudios sobre historia del paisaje español. ORTEGA CANTERO, N. (coord.). Madrid: 2002, pp. 115-154.

${ }^{21}$ Al matrimonio Humboldt, por ejemplo, no les satisfizo Sevilla — «gran ciudad de calles estrechas y sombrías» escribía Carolina en una carta (Farinelli, op. cit, nota 6, p.142) mientras que Cádiz para Washington Irving fue la ocasión de tratar al sabio hispanista Böhl von Faber. 
«mitológico»y que, durante el primer tercio del XIX, se había hecho famosa por los asedios de los ejércitos franceses y la reunión de las Cortes que promulgaron la primera Constitución española.

La riqueza económica que el comercio marítimo reportaba a la ciudad de Hércules, su disposición de pequeña península rodeada por el mar y la actividad naviera de su bahía y de los lugares más próximos fascinaba a muchos de sus visitantes, que si accedían a Cádiz desde el Puerto de Santa María, podían sentir más directamente los efectos del viento sobre barcos, falucas y viajeros ${ }^{22}$, o tener la impresión de haber adquirido una gran lección para la vida, como anotaba el argentino Domingo Faustino Sarmiento en su resumen de la visita a la ciudad y a la región andaluza que el argentino veía como una reencarnación del orientalismo:

Y luego, las mujeres andaluzas, graciosas como bayaderas, locas por el placer como las orientales, y aquel pueblo que canta todo el día, ríe, riñe y miente con un aplomo que asombra. ¡Oh, las hipérboles andaluzas dejarían atónitos a los más hiperbólicos asiáticos! ¡Qué imaginación, qué riquezas de espíritu! ¡Qué feliz es la alegre Andalucía! Al salir de España, siento que toda ella se resume en mi espíritu en estos raros aforismos ${ }^{23}$.

La luminosidad y el color, como hemos visto más arriba, son trazos imprescindibles en la caracterización del Sur que, por supuesto, aparecen en la percepción imaginística que tienen de Cádiz algunos viajeros. Valga este testimonio de los diarios de Ticknor que corresponde a su llegada a la ciudad el día cinco de octubre de 1818:

Tras pasar la isla de León, la bahía de Cádiz, sus embarcaciones, toda la amplitud del océano y la ciudad misma saliendo de él «como una bella exhalación» que parecía bailar como una visión sobre las ondulaciones de sus olas, surgieron de repente ante mi vista. Crucé el istmo fortificado que los franceses nunca fueron capaces de traspasar y, entre las ocho y las nueve de la mañana, llegué a la ciudad $^{24}$.

Ahora bien, las connotaciones marítimas son las que sirven campo más amplio para las construcciones metafóricas empleadas por los viajeros. El ya

${ }^{22}$ El newyorquino Alexander Slidell Mackenzie describía su pasaje de la bahía en estos términos: «There was scarce a breath of wind in the bay of Cadiz, and the inward and outward bound vessels stood still with flapping sails, or only moved with the tide, whilst a boat was seen rowing under the bow of each to keep it in the channel. This being the case, we did not loose our sail, but he rowers took to their oars to toil over to the city, which lies eight miles from Santa María» (A year in Spain by a young American. Boston: Killiard, Gray, 1829, p. 306).

${ }^{23}$ SARMIENTO, «Viajes por Europa, África y América». En: SORENSEN, Diana (ed.). Obras Selectas. Madrid: Espasa-Biblioteca de Literatura Universal, 2002, p. 413. En este texto y en las citas de los textos que siguen subrayo las palabras que enuncian la visión metafórica.

${ }^{24}$ Según la traducción a la que se alude en nota 15. 
citado Longfellow, por ejemplo, ve el conjunto urbano gaditano como una atractiva concha marina que pone en relación con las fantasías oníricas:

Cadiz is beautiful almost beyond imagination. The cities of our dreams are not more enchanting. It lies like a «delicate sea-shell» upon the brink of the Ocean, so wondrous fair that it seems not formed for man (...). It is the city of beauty and of love ${ }^{25}$.

Otros viajeros relacionan la ciudad con un barco. En un pasaje de su novela Atar-Gull, había recordado esta imagen, en clave jocosa, el folletinista Eugène Sue recordando su intervención como uno de los «cien mil hijos de San Luis» que asediaron Cádiz en 1823:

Nous relâcherons à Cádiz... Ah! capitaine...capitain, je vous vois déjà sur la place San Antonio...Tonerre du diable... c'est là qu'il y a des femmes! Des yeux grands comme les écubiers d'une frégate, les dents comme des râteliers de tournage, et puis comme dit la chanson:

$$
\begin{aligned}
& \text { Y una popa, } \\
& \text { caramba, } \\
& \text { como un bergantín }{ }^{26} \text {. }
\end{aligned}
$$

Y una viajera británica, lady Emmeline Stuart-Wortley, repetía la imagen en su libro de 1856 The Sweet South añadiendo otra comparación:

Los españoles parecen sentir una gran admiración por Cádiz. En algunos de sus libros lo comparan a «un palacio de plata colgado sobre el mar» y primorosamente afiligranado. También dicen que, visto desde otras perspectivas y a causa de sus torres blancas, altas y esbeltas, las azoteas de sus casas y las cúpulas de sus gráciles templos «semejan un gran navío de alabastro o marfil» que brilla esplendoroso y se eleva flotando en medio del mar azul. Las cúpulas y los templos supongo yo que quieren representar, de manera bastante imperfecta, claro, las velas blancas tensadas por el viento. Aunque después de todo no hay tanta exageración en esta descripción teniendo en cuenta el amor que los españoles sienten por el lenguaje de estilo oriental ${ }^{27}$.

Belleza natural irrepetible de las mujeres gaditanas y lenguaje e imaginación orientales, referentes a los que remiten los dos últimos textos citados, forman parte del estereotipo más establecido que reiteró la percepción del Sur andaluz en muchos de sus visitantes. Recuérdese la fascinación que Cádiz ejerció sobre el lord Byron que el once de agosto de 1809 escribía a su madre «Cadiz, sweet Cadiz! Is the most delightful town I ever beheld» y que, como poeta, cantaría la belleza de las mujeres hispanas en

\footnotetext{
${ }^{25}$ Op. cit. nota 14 , p. 118.

${ }^{26}$ BORY, Jen-Louis. Eugène Süe, le roi du roman populaire. Hachette, 1962.

${ }^{27}$ Doy el texto traducido en el volumen Viajeras anglosajonas en España. Egea Fernández-Montesinos, Alberto (coor.). Sevilla: Centro de Estudios Andaluces, 2009, p. 139.
} 
varias estrofas de Childe Harold's pilgrimage $e^{28}$ o que en su travesía mediterránea en el paquebote Townshend iniciaría su poema arquetípico «The Girl of Cadiz» con estos versos, en los que de nuevo se alude a la bipolaridad Norte/Sur:

Oh, never talk again to me of northern climes and british ladies.

Lo vivido en un sueño, en fin, era la explicación que muchos viajeros daban a su viaje meridional. Richard Trench, desde las brumosas calles londinense escribía a su amigo John Sterling, visitante de Andalucía, «do not came back to England as long as you cand find anything in the world to interest you. When you have ceased to do so, come hither; I will give you weak tea and dream of Spain while you describe it» ${ }^{29}$. Y el romántico galo Théophile Gautier concluía así su memorable Voyage en Espagne de 1843:

Le lendemain, à dix heures du matin, nous entrions dans la petite anse au fond de laquelle s'épanouit Port-Vendres. Nous étions en France. Vous le dirai-je? en mettant le pied sur le sol de la patrie, je me sentis des larmes aux yeux, non de joie, mais de regret. Les Tours Vermeilles, les sommets d'argent de la Sierra Nevada, les lauriers-roses du Generalife, les longs regards de velours humide, les lèvres d'oeillet en fleur, les petits pieds et les petites mains, tout cela me revint si vivement à l'esprit, qu'il me sembla que cette France, où pourtant $\mathrm{j}$ 'allais retrouver ma mère, était pour moi une terre d'exil. Le rêve était fini ${ }^{30}$.

\section{REFERENCIAS BIBLIOGRÁFICAS}

ANDERSEN, Hans Cristian. Viaje por España. Rey, Marisa (trad.). Madrid: Alianza, 2005. AZORÍN. Los pueblos. La Andalucía trágica y otros artículos (1904-1905). Valverde, J. M $^{\text {a }}$ (ed.). Madrid: Castalia, 1973.

BORY, Jen-Louis. Eugène Süe, le roi du roman populaire. Hachette, 1962.

CHEVENIX TRENCH, Richard. Letters and memorials. London, 1888, vol. I.

DOMÍNGUEZ, César. «The South European Orient: A Comparative Reflection on Space in Literaay History». Modern Language Quarterly, 2006, 67-4, pp. 419-449.

EGEA FERNÁNDEZ-MONTESINOS, Alberto. (Coor.). Viajeras anglosajonas en España. Sevilla: Centro de Estudios Andaluces, 2009.

FARINELLI. Guillaume de Humboldt et l'Espagne. Avec une esquisse sur Goethe et l'Espagne. Torino: Boca, 1924.

GAUTIER, Théophile. Voyage en Espagne. Berthier, P. (ed.). Paris: Gallimard, 1981.

GOETHE, Johann Wolfgang. Goethes Briefe. Hamburg: Wegner, 1963, vol. III.

${ }^{28}$ ROSCOE, Thomas. (Op. cit. en nota 19, pp. 254-255) en un ejercicio de reescritura de otro texto de viaje, evocaría la belleza de las gaditanas a partir de la estrofa LXVII del Childe Harold, la dedicada a la «maid of Saragosse».

${ }^{29}$ CHEVENIX TRENCH, Richard. Letters and memorials. London, 1888, vol. I, p. 29.

${ }^{30}$ GAUTIER, Théophile. Voyage en Espagne. Berthier, P. (ed.). Paris: Gallimard, 1981, p. 450. 
IRVING, Washington. Diary. Spain 1828-1829. New York: The Hispanic Society of America, 1928.

KRAUEL, Blanca. Viajeros británicos en Málaga (1760-1855) Málaga: Diputación Provincial, 1988.

LEGUEN, B. «Madame de Staël en la encrucijada de las Literaturas del Norte y del Sur». AA.VV. Estudios de Literatura Comparada (...). En: Actas del XIII Simposio de la Sociedad Española de Literatura General y Comparada. León: Universidad, 2002, pp. 171-182.

LONGFELLOW, Henry H. Outre-mer. A pilgrimage beyond the sea. Boston-New Yok, 1891.

LÓPEZ ONTÍVEROS, Antonio. «Del prerromanticismo al romanticismo: el paisaje de Andalucía en los viajeros de los siglos XVIII y XIX». En: AA.VV. Estudios sobre historia del paisaje español. ORTEGA CANTERO, N. (coord.). Madrid: 2002, pp. 115-154.

ORTAS, Esther. Viajeros ante el paisaje aragonés (1759-1850). Zaragoza: Institución Fernando el Católico, 1999.

PITOLLET, Camille. La querelle caldéronienne de Johan-Nikolas Böhl von Faber et José Joaquín de Mora. Reconstituée d'après les documents originaux. Paris: Alcan, 1909.

ROMERO TOBAR, Leonardo. «Romanticismo e idea de España y la nación española». Madrid: Fundación Ortega y Gasset, 2011, en prensa.

SARMIENTO, Domingo Faustino. «Viajes por Europa, África y América». En: SORENSEN, Diana (ed.). Obras Selectas. Madrid: Espasa-Biblioteca de Literatura Universal, 2002, p. 413.

SLIDELL MACKENZIE. A year in Spain by a young American. Boston: Killiard, Gray, 1829.

STAËL, Mme. De l'Allemagne. Paris: Hachette, 1959, III.

TICKNOR, G. Diary de Ticknor. Martín Ezpeleta, Antonio (ed. y trad.). (Edición completa del manuscrito original conservado en la biblioteca de la Universidad de Darmouth y que se publicará en la serie «Clío y Calíope» de las Prensas Universitarias de Zaragoza.

Fecha de recepción: 29 de enero de 2010

Fecha de aceptación: 8 de septiembre de 2010 